Published in:

C. Lautenberger, G. Rein and C. Fernandez-Pello, Fire Safety Journal 41 (2006), pp. 204-214.

\title{
The Application of a Genetic Algorithm to Estimate Material Properties for Fire Modeling from Bench-Scale Fire Test Data
}

\author{
Chris Lautenberger, Guillermo Rein, and Carlos Fernandez-Pello* \\ Department of Mechanical Engineering, \\ University of California, Berkeley \\ Berkeley, CA 94720, USA.
}

*Corresponding author. Tel: 510-642-6554; Fax: 510-642-1850; Email: ferpello@me.berkeley.edu.

\begin{abstract}
A methodology based on an automated optimization technique that uses a genetic algorithm (GA) is developed to estimate the material properties needed for CFD-based fire growth modeling from bench-scale fire test data. The proposed methodology involves simulating a bench-scale fire test with a theoretical model, and using a GA to locate a set of model parameters (material properties) that provide optimal agreement between the model predictions and the experimental data. Specifically, a genetic algorithm based on the processes of natural selection and mutation is developed and integrated with the NIST FDS v4.0 pyrolysis model for thick solid fuels. The combined genetic algorithm/pyrolysis model is used with Cone Calorimeter data for surface temperature and mass loss rate histories to estimate the material properties of two charring materials (redwood and red oak) and one thermoplastic material (polypropylene). This is done by finding the parameter sets that provide near-optimal agreement between the model predictions and experimental data given the constraints imposed by the underlying physical model and the accuracy with which the boundary and initial conditions can be specified. The methodology is demonstrated here with the FDS pyrolysis model and Cone Calorimeter data, but it is general and can be used with several existing fire tests and almost any pyrolysis model. Although the proposed methodology is intended for use in CFD-based prediction of large-scale fire development, such calculations are not performed here and are recommended for future work.
\end{abstract}

Key Words: genetic algorithms, pyrolysis, material fire properties, Cone Calorimeter, FDS 


\section{Nomenclature}

\section{Letters}

a Parameter (gene)

$A \quad$ Individual (chromosome)

$B$ Population of individuals (chromosomes) selected for reproduction

$C$ Intermediate population

c Specific heat $[\mathrm{kJ} / \mathrm{kg} \cdot \mathrm{K}]$

$E_{A} \quad$ Activation energy $[\mathrm{kJ} / \mathrm{mol}]$

$\tilde{f} \quad$ Fitness of an individual at one heat flux level

$f \quad$ Fitness of an individual, weighted over all heat flux levels

$h \quad$ Convective heat transfer coefficient at front face of fuel sample $\left[\mathrm{W} / \mathrm{m}^{2} \cdot \mathrm{K}\right]$

$\Delta H \quad$ Latent heat $[\mathrm{kJ} / \mathrm{kg}]$

$k \quad$ Thermal conductivity $[\mathrm{W} / \mathrm{m} \cdot \mathrm{K}]$

$\ell \quad$ Generation index

$\dot{m}^{\prime \prime} \quad$ Pyrolyzate flux rate $\left[\mathrm{kg} / \mathrm{m}^{2} \cdot \mathrm{s}\right.$ or $\left.\mathrm{g} / \mathrm{m}^{2} \cdot \mathrm{s}\right]$

$n \quad$ Number of parameters (genes) per individual

$n_{\dot{q}_{e}^{\prime \prime}} \quad$ Number of heat flux levels used for fitness evaluation

$N \quad$ Number of individuals (chromosomes) per population

$p \quad$ Probability

$q \quad$ See Eq. 13

$\dot{q}^{\prime \prime} \quad$ Heat flux $\left[\mathrm{kW} / \mathrm{m}^{2}\right]$

$r \quad$ Array or matrix of random real numbers

$R \quad$ Universal gas constant $[\mathrm{kJ} / \mathrm{mol} \cdot \mathrm{K}]$

$R^{2} \quad$ Coefficient of determination [-]

$s \quad$ Single random real number

$S \quad$ Target (maximum) selection number of an individual

$t \quad$ Time [s]

$T \quad$ Temperature $[\mathrm{K}]$

$v \quad$ Velocity $[\mathrm{m} / \mathrm{s}]$ or mutation severity

$X \quad$ Volume fraction $\left[\mathrm{m}^{3} / \mathrm{m}^{3}\right]$

$y \quad$ Measured or predicted value at a point in time

$z \quad$ Spatial coordinate $[\mathrm{m}]$

$Z \quad$ Pre-exponential factor $[\mathrm{m} / \mathrm{s}]$

\section{Greek Symbols}

$\alpha \quad$ Thermal diffusivity $\left[\mathrm{m}^{2} / \mathrm{s}\right]$

$\delta \quad$ Thickness [m]

$\varepsilon \quad$ Surface emissivity [-]

$\rho \quad$ Density $\left[\mathrm{kg} / \mathrm{m}^{3}\right]$

$\sigma \quad$ Stefan-Boltzmann constant $\left[\mathrm{W} / \mathrm{m}^{2} \cdot \mathrm{K}^{4}\right]$

$\zeta \quad$ See Eq. 10 


\section{$\underline{\text { Subscripts }}$}

$\begin{array}{ll}0 & \text { Initial } \\ \infty & \text { Ambient } \\ c & \text { Char } \\ e & \text { External } \\ \text { exp } & \text { Experimental value } \\ f & \text { Pyrolysis front } \\ f l & \text { Flame } \\ g & \text { Gaseous pyrolysate } \\ j & \text { Gene } j \\ \max & \text { Maximum } \\ \min & \text { Minimum } \\ m u t & \text { Mutation } \\ p & \text { Pyrolysis } \\ s & \text { Surface } \\ \text { sel } & \text { Selection } \\ t r y & \text { Trial value } \\ v & \text { Virgin }\end{array}$

\section{$\underline{\text { Superscripts }}$}

* $\quad$ See Eq. 1

try Trial value

act Actual (experimental) value

( ) Averaged

I Individual $I$ 


\section{Introduction}

There is substantial interest in using CFD-based fire modeling to predict flame spread and fire growth in real-world geometries and actual environments. This is potentially useful for fire safety engineering when it is not practical to perform full-scale fire testing due to cost or size. Particularly in the early phases of product development, fire modeling provides a cost-effective alternative to expensive full-scale fire tests required by building codes and other regulations for material certification, and can reduce the time to market. Also, computer fire models can be used predict fire development in environments that are difficult to reproduce in the laboratory. An example of particular interest to the authors is the extrapolation of normal gravity flammability data to reduced gravity environments such as those encountered in spacecraft [1] where testing is prohibitively expensive if not outright impossible.

One of the biggest impediments preventing increased usage of CFD-based fire growth modeling is our limited ability to use data from common bench-scale fire tests, such as the Cone Calorimeter [2] and Fire Propagation Apparatus [3], to characterize practical materials in terms of the solid phase "material properties" needed by the simplified numerical pyrolysis models embedded in CFD codes. Although techniques have been developed to estimate several material fire properties from laboratory fire tests, as will be discussed further in Section 2.2 there is a disconnect between the material properties needed for CFD-based fire modeling and those properties that can be determined with existing methods. 
The main contribution of this paper is the development of a methodology based on an automated optimization technique that uses a genetic algorithm (GA) to estimate the material properties required for CFD-based fire growth modeling from bench-scale fire test data. Genetic algorithms are a class of search tools that use the principles of Darwinian evolution to seek an optimal solution to a problem having a large number of adjustable parameters. In comparison to many traditional search methods, genetic algorithms can handle nonlinear problems and search spaces having high dimensionality. The proposed methodology involves simulating a benchscale fire test with a theoretical model and using a GA to locate a set of model parameters (material properties) that provide optimal agreement between the model predictions and the experimental data subject to the constraints imposed by the underlying physical model. The material properties found by the genetic algorithm will be close to the "actual" values provided the experimental measurements are sufficiently accurate and contain enough information to establish a unique set of model parameters, the pyrolysis model is an adequate representation of the underlying physical processes, and the specified boundary and initial conditions are an accurate representation of the experimental configuration. This approach is self-consistent in the sense that the same model that is used to estimate the material properties from small-scale experimental data can be coupled to a CFD code to model large-scale fire development.

Here, the proposed methodology is used with the NIST FDS v4.0 thick solid fuel pyrolysis model [4] and Cone Calorimeter [2] data. Specifically, the pyrolysis model is used to calculate the solid fuel's surface temperature and mass loss rate histories, which are then compared with the corresponding Cone Calorimeter data. A genetic algorithm is used to find the material properties that provide optimal agreement between the pyrolysis model predictions and the Cone 
Calorimeter data. It should be emphasized, however, that the methodology is general and can be applied to several existing fire tests and used with almost any pyrolysis model. Whether a particular fire test or pyrolysis model is applicable for prediction of large scale fire development is an important issue that is not considered here.

\section{Simulating a bench-scale fire test with a one-dimensional pyrolysis model}

The physical problem being modeled is that of a combustible solid being tested in the Cone Calorimeter, i.e. the radiative heating, pyrolysis, and combustion of solid fuel slab. A simplified schematic is given in Fig. 1. The sample thickness $\delta$ is small in comparison with its length and width. Edge effects are not considered and the problem is therefore treated as one-dimensional. The irradiated face of the sample is located at $z=0$, and its back face abuts a perfectly thermally insulative substrate at $z=\delta$. The solid fuel is approximated as spectrally gray and opaque to thermal radiation so that radiative absorption occurs only at the surface. A particular fire test is modeled by applying a specific set of initial and boundary conditions that describe the initial state $\left(T_{0}\right)$, the convective environment $\left(h, T_{\infty}\right)$, and the applied external radiation level $\left(\dot{q}_{e}^{\prime \prime}\right)$.

Prior to ignition, the fuel is heated only by the externally applied radiation; after ignition, it is also heated by heat feedback from the flame $\left(\dot{q}_{f l}^{\prime \prime}\right)$. The flame heat flux varies from apparatus to apparatus, and for a particular apparatus it depends on the fuel type, the instantaneous heat release rate, and environmental conditions (particularly ambient $\mathrm{O}_{2}$ concentration). In this work, the approximation is made that the flame heat flux is fuel independent, spatially uniform, and 
temporally invariant. It is assumed to be negligible prior to ignition, instantaneously jumping to a constant value at the observed ignition time.

Several pyrolysis models are appropriate for simulating the physical problem in this simplified form, but in this work a standalone implementation of the NIST FDS v4.0 pyrolysis model for thermally thick solid fuels [4] is used. The major equations (which are spatially discretized with finite differences and then integrated in time) are summarized below.

\subsection{Simplified pyrolysis model}

The NIST FDS v4.0 charring pyrolysis model [4] is based on the work of Atreya [5] as modified by Ritchie et al. [6]. It tracks the position of the pyrolysis front, a sharp demarcation between the virgin and char phases. These phases have different densities, and may also have different thermal conductivities and specific heats. The following form of the energy equation is solved:

$$
\begin{gathered}
\rho c \frac{\partial T}{\partial t}=\frac{\partial}{\partial z}\left(k \frac{\partial T}{\partial z}\right)-\dot{m}^{\prime \prime \prime}\left(\Delta H_{p}-\Delta H_{p}^{*}\right) \\
\Delta H_{p}^{*}=\left(\frac{\rho_{v} c_{v}-\rho_{c} c_{c}}{\rho_{v}-\rho_{c}}-\overline{c_{g}}\right)\left(T-T_{0}\right)
\end{gathered}
$$

A subscript $v$ denotes the virgin material, a subscript $c$ denotes the char phase, and a subscript $g$ denotes the gaseous pyrolysate. Quantities without a subscript are total quantities that apply locally to the solid as a whole. Although the model can accommodate temperature-dependent solid phase thermal properties, in this work it is assumed that all thermal properties do not vary 
with temperature with the exception of $c_{g}$ (the specific heat of the gaseous pyrolysate vapors). This quantity is evaluated at the average of the initial temperature $T_{0}$ and the local temperature $T$.

Denoting $T(0, t)$ as $T_{s}$, the initial and boundary conditions applied to Eq. 1 are:

$$
\begin{gathered}
T(z, 0)=T_{0} \\
-\left.k \frac{\partial T}{\partial z}\right|_{z=0}=\varepsilon \dot{q}_{e}^{\prime \prime}-h\left(T_{s}-T_{\infty}\right)-\varepsilon \sigma\left(T_{s}^{4}-T_{\infty}^{4}\right) \\
-\left.k \frac{\partial T}{\partial z}\right|_{z=\delta}=0
\end{gathered}
$$

Since the virgin fuel and char may have different thermophysical properties, the local volumeaveraged thermal conductivity and product of density and specific heat must be determined in each cell:

$$
\begin{gathered}
k=k_{v}\left(1-X_{c}\right)+k_{c} X_{c} \\
\rho c=\rho_{v} c_{v}\left(1-X_{c}\right)+\rho_{c} c_{c} X_{c}
\end{gathered}
$$

where $X_{c}$ is the local char volume fraction. Denoting $z_{f}$ as the position of the pyrolysis front, the char volume fraction is:

$$
X_{c}= \begin{cases}1 & z<z_{f} \\ 0 & z \geq z_{f}\end{cases}
$$

Although the pyrolysis front is assumed to be infinitely thin, the grid cells used to discretize and solve the governing equation have a finite thickness. Thus, only for the grid cell in which the pyrolysis front is located, the char volume fraction falls between 0 and 1 and is equal to the spatially-weighted char volume fraction. 
The volatiles generated in-depth are instantaneously transported to the surface, and the mass loss rate per unit area is calculated as an Arrhenius function of the pyrolysis front temperature $T_{f}$ (determined by interpolation):

$$
\dot{m}^{\prime \prime}=\left(\rho_{v}-\rho_{c}\right) Z \exp \left(-\frac{E_{A}}{R T_{f}}\right)
$$

The volumetric pyrolysis reaction rate appearing in Eq. 1 is calculated from $\dot{m}^{\prime \prime}$ :

$$
\dot{m}^{\prime \prime \prime}= \begin{cases}\dot{m}^{\prime \prime} / \Delta z & \text { for cell containing pyrolysis front } \\ 0 & \text { in all other cells }\end{cases}
$$

where $\Delta z$ is the grid spacing in the cell containing the pyrolysis front.

The preceding formulation is valid for modeling the pyrolysis of charring fuels. For modeling the pyrolysis of noncharring fuels, the FDS "thermoplastic" pyrolysis model can be recovered by setting $\Delta H_{p}^{*}=0$ in Eq. $1, z_{f}=0$ in Eq. 5 (leading to $X_{c}=0 \forall z, k=k_{v}, \rho c=\rho_{v} c_{v}$, and $T_{f}=T_{s}$ ), and $\rho_{c}=0$ in Eq. 6. Thus, the thermoplastic model can be thought of as a special case of Eqs. $1-7$. Its primary limitations are: 1) surface regression is not accounted for, i.e. the fuel thickness remains equal to its initial thickness regardless of the amount of solid fuel consumption, and 2) all pyrolysis is assumed to occur at the fuel surface, i.e. the pyrolysis rate is a function only of the surface temperature (it has been experimentally demonstrated that this is not the case [7]).

\subsection{Required material properties}


In the present work, the pyrolysis model is used to calculate the material surface temperature and mass loss rate histories as a function of the material properties. In terms of the material properties needed to characterize a particular material, the FDS pyrolysis model described above is fairly typical of other models based on similar formulations. It can be seen from above that at least five material properties are needed to simulate the pyrolysis of a noncharring material: thermal conductivity $\left(k_{v}\right)$, specific heat $\left(c_{v}\right)$, pre-exponential factor $(Z)$, activation energy $\left(E_{A}\right)$, and heat of pyrolysis $\left(\Delta H_{p}\right)$. At least three additional properties are needed to model a charring material: char thermal conductivity $\left(k_{c}\right)$, char specific heat $\left(c_{c}\right)$, and char density $\left(\rho_{\mathrm{c}}\right)$. Our inability to estimate all of these properties from bench-scale fire tests, discussed briefly below, is one of the primary motivations of this work.

Thermal ignition theories (e.g. Ref. [8]) can be used to determine a material's apparent thermal inertia (the product $k \rho c$ ) by plotting ignition time data at multiple heat flux levels, but numerical pyrolysis models require specification of individual thermal properties $\left(k_{v}, \rho_{v}, c_{v}\right)$. Furthermore, the derived $k \rho c$ is an effective value that depends on the data reduction technique used [9] and environmental conditions [10]. Being an effective value, it also includes the endothermicity of the pyrolysis reaction, which is treated explicitly in a numerical model. Since the effective thermal inertial is derived from a thermally thick analysis using a linearized total heat transfer coefficient, it has limited usefulness for numerical modeling where nonlinear surface re-radiation is treated explicitly [11] (as in numerical pyrolysis modeling) and for non-thick materials. A perhaps more significant limitation is that although charring materials account for a large fraction of the materials encountered in practice, there are no procedures available to estimate the 
thermal conductivity, density, and specific heat, and density of the char phase $\left(k_{c}, \rho_{c}, c_{c}\right)$ from fire test data.

Similarly, there are currently no procedures available that use laboratory fire test data to estimate the Arrhenius pyrolysis rate coefficients $\left(Z, E_{A}\right)$. They are usually determined by thermogravimetric analysis that involves slowly heating very small samples with a mass of a few milligrams and measuring the resultant mass loss [12]. Since heat and mass transfer processes are expected to be much different in milligram size samples and the bulk material's end-use configuration, the relevancy of these measurements to the pyrolysis and combustion of large samples under fire-level heating rates is questionable.

The heat of pyrolysis $\Delta H_{p}$ (the heat required to convert unit mass of solid material at its pyrolysis temperature to unit mass of pyrolysate and char) is generally used to characterize the endothermicity of the pyrolysis reaction. However, $\Delta H_{p}$ cannot be directly determined from fire tests with existing procedures. Only the effective heat of gasification (the heat required to raise unit mass of material from its initial temperature to its pyrolysis temperature plus the heat of pyrolysis) can be determined from fire test data [13]. Furthermore, it is not clear whether this procedure can be effectively applied to charring materials that do not show a steady-state burning phase.

\section{A genetic algorithm for automated optimization}


In this section, a methodology is presented that can be used to estimate the unknown material properties identified above from fire test data. It involves using a genetic algorithm to find a set of properties that provides near-optimal agreement between the predictions of a numerical pyrolysis model and experimental measurements from a fire test. However, the inverse problem being solved is ill-posed. That is, the solution (the set of material properties) is not necessarily unique and it is not necessarily stable to small changes in the input data. The proposed methodology is heuristic, meaning that the final solution is not necessarily the absolute optimal solution; however, the algorithm will find a solution that gives a near-optimal prediction of the experimental data given the constraints of the underlying physical model, i.e. the results are almost as good as those that would be obtained with the optimal solution.

Genetic and evolutionary algorithms have been widely used in engineering. They have already been applied to the optimization of combustion and chemical kinetics problems, including heterogeneous [14] and homogeneous [15] reaction mechanisms. The authors have used a GA to extract detailed decomposition kinetics of polyurethane foam from thermogravimetric experiments [16]. However, since the use of a GA to estimate solid-phase material properties from fire test data is a specialized application, the algorithm is described in detail below. The reader desiring a general treatment of genetic or evolutionary algorithms is referred to several books covering the topic $[17,18,19]$.

\subsection{Initial population}


The search process is initialized by randomly generating several candidate solutions (for a charring material, a vector of eight real numbers corresponding to $\left.k_{v}, c_{v}, Z, E_{A}, \Delta H_{p}, k_{c}, \rho_{c}, c_{c}\right)$. Each candidate solution is referred to as an individual or a chromosome, and the terms are used interchangeably throughout the genetic algorithms literature. A single parameter of an individual (or chromosome) is referred to as a gene, i.e. the numerical value of the virgin phase thermal conductivity is one gene. The entire group of candidate solutions is referred to as a population. Typical population sizes range from tens to hundreds of individuals. Populations constantly evolve to form subsequent generations; the initial population is the first generation, the offspring of the first generation make up the second generation, and so on.

Let $\left\{a_{1}, a_{2} \ldots a_{n}\right\}$ denote the $n$ parameters, or genes, that make up an individual, or chromosome. Here, $a_{1}$ may be associated with $k_{v}, a_{2}$ with $c_{v}$, and so on. For certain variables that may take on values over several orders of magnitude, it is convenient to have the gene represent the logarithm of that variable. Let $\left\{A^{1}, A^{2} \ldots A^{N}\right\}$ denote the $N$ individuals that make up the population. The nomenclature $A^{I}(\ell)$ is used to denote the $I^{\text {th }}$ individual of generation $\ell$. Similarly, $A_{j}^{I}(\ell)$ represents the $j^{\text {th }}$ gene of the $I^{\text {th }}$ individual of generation $\ell$.

Begin by generating an initial population:

$$
A_{j}^{I}(1)=a_{j, \min }+r_{j}^{I}\left(a_{j, \max }-a_{j, \min }\right)
$$

The parameters $a_{j, \max }$ and $a_{j, \min }$ are the user-specified upper and lower bounds of each variable; all parameters are constrained by these values throughout the evolution process. In Eq. $8, r_{j}^{I}$ is an $N$ by $n$ matrix of random real numbers distributed uniformly on the interval $[0,1]$. The indices $I$ and $j$ are cycled from 1 to $N$ and 1 to $n$, respectively. 


\subsection{Fitness}

Next, the fitness of each individual is evaluated. Here, fitness is a measure of how well the candidate solution matches the experimental data. It is assumed that at a minimum, surface temperature and mass loss rate histories are available (additional temperature measurements could certainly be used). The coefficients of determination $\left(R^{2}\right.$ values) that measure the level of agreement between the measured surface temperature/mass loss rate histories and the predictions of individual $I$ are:

$$
\begin{aligned}
& {R_{T_{s}}^{2 I}}^{I}=\frac{\sum\left(T_{\text {sexp }}-\overline{T_{s, e x p}}\right)^{2}-\sum\left(T_{s, e x p}-\overline{T_{s, t r y}}\right)^{2}}{\sum\left(T_{\text {sexp }}-\overline{T_{s, e x p}}\right)^{2}} \\
& {R_{\dot{m}^{\prime \prime}}^{2 I}}^{I^{\prime}}=\frac{\sum\left(\dot{m}_{\text {exp }}^{\prime \prime}-\overline{\dot{m}_{\text {exp }}^{\prime \prime}}\right)^{2}-\sum\left(\dot{m}_{\text {exp }}^{\prime \prime}-\overline{\dot{m}_{t r y}^{\prime \prime}}\right)^{2}}{\sum\left(\dot{m}_{\text {exp }}^{\prime \prime}-\overline{\dot{m}_{\text {exp }}^{\prime \prime}}\right)^{2}}
\end{aligned}
$$

Here, a subscript "exp" denotes the experimental data, and a subscript "try" denotes the trial solution generated by a certain set of parameters contained in the individual. Eq. 9 is written as a summation, rather than an integral, because experimental measurements are obtained at discrete time intervals. In Eq. 9a, the summation is performed for surface temperature measurements/predictions only before the experimentally determined ignition time, but in Eq. $9 \mathrm{~b}$ the summation for the mass loss rate measurements/predictions is carried out over the entire duration of the test. This choice was made because the accuracy of surface temperature measurement becomes more questionable after ignition. The use of a simple $R^{2}$ value for 
evaluating the fitness is somewhat arbitrary; other methods of calculating the residual could also be used.

Next, the weighted fitness of individual $I$ is calculated as:

$$
\widetilde{f}^{I}=\left(\phi_{T_{s}} R_{T_{s}}^{2 I}\right)^{\xi}+\left(\phi_{\dot{m}^{\prime \prime}} R_{\dot{m}^{\prime \prime}}^{2 I}\right)^{\xi}
$$

In Eq. 10, $\zeta$ is a user-specified exponent, and the $\phi$ factors are user-specified constants that determine the relative importance of each fitness metric such that $\Sigma \phi_{i}=1$. If experimental data are obtained at multiple heat flux levels, then an individual's final fitness is considered to be the averaged fitness at all heat flux levels:

$$
f^{I}=\frac{1}{n_{\dot{q}_{e}^{\prime \prime}}} \sum_{n_{q_{e}^{*}}} \widetilde{f}^{I}
$$

where $n_{\dot{q}_{e}^{\prime \prime}}$ is the number of heat flux levels at which data were obtained. The steps represented by Eqs. 9 through 11 are then repeated for all individuals to tabulate a numerical fitness value for each individual.

\subsection{Selection for reproduction}

The next generation is obtained through the process of reproduction wherein parents' genes are combined to produce offspring. The likelihood that an individual reproduces is determined by its fitness. In this way, relatively bad candidate solutions die out, while relatively good solutions survive and propagate. This "natural selection" process is the basis of genetic algorithms' ability to exploit good solutions. 
There are many different ways in which individuals can be selected for reproduction, but proportional selection [19] was used here for simplicity. The selection probability of individual $I$ is:

$$
p_{\text {sel }}^{I}=\frac{f^{I}}{\sum_{I=1}^{N} f^{I}}
$$

Thus, the higher an individual's fitness, the greater the probability it will be selected for reproduction. In practice, the selection probability in Eq. 12 is implemented by first sorting the current population in order of decreasing fitness, i.e. $f^{I} \geq f^{I+1}$. Then, for each individual, the following is calculated:

$$
q^{I}=\sum_{i=I}^{N} p_{s e l}^{i}
$$

Note that by definition, $q^{1}=1$ and $q^{N}=p_{s e l}^{N}$. Next, a random number $r$ belonging to a uniform distribution is generated on the interval $[0,1]$. Selection proceeds by comparing $r$ with $q$ : if $q^{I+1}$ $<r \leq q^{I}$, then $A^{I}$ is selected for reproduction. The selection process is repeated $N$ times to choose $N$ parents.

If one individual has a relative fitness much higher than the average, it is likely that this individual will be selected several times for reproduction. To prevent premature convergence, a target (maximum) selection number $S$ is used so that any individual may be selected for reproduction no more than $S$ times per generation $(1 \leq S<N)$. If an individual has reproduced $S$ times and is selected again for reproduction, then a new individual is randomly selected from the population for reproduction. Low values of $S$ preserve variability at the expense of convergence. 


\subsection{Reproduction}

Once individuals have been selected for reproduction, offspring are generated through a linear combination of two parents. Denote $\{B\}$ the subset of population $\{A\}$ that was selected for reproduction. As many as $S$ copies of a single individual may belong to the set $\{B\}$. The offspring are stored in a temporary intermediate population denoted $\{C\}$. This is accomplished by generating a matrix of random numbers (denoted $r_{j}^{i}$ where $i=1 \ldots N / 2$ and $j=1 \ldots n$ ) belonging to a uniform distribution on the interval $[-0.5,0.5]$ and then producing offspring as linear combinations of the parents:

$$
\begin{aligned}
& C_{j}^{I}=r_{j}^{i} B_{j}^{I}+\left(1-r_{j}^{i}\right) B_{j}^{I+1} \\
& C_{j}^{I+1}=r_{j}^{i} B_{j}^{I+1}+\left(1-r_{j}^{i}\right) B_{j}^{I}
\end{aligned} \quad \text { for } I=1,3,5 \ldots N-1 \quad \text { where } \quad i=\frac{I+1}{2}
$$

\subsection{Mutation}

After two parents have combined to produce a new individual, a process analogous to genetic mutation is used to introduce variability into the population, which ensures the entire search space is explored and that the solution does not become trapped at a local maximum. Mutation is accomplished by introducing random variations into one or more of an individual's genes. The probability that a gene is mutated is relatively low, perhaps 0.05 . Mutation is performed on a gene-by-gene basis. At the start of the calculation, each parameter (gene) is assigned a userspecified mutation probability $p_{m u t, j}$. Mutation is performed on the intermediate population $\{C\}$ and begins by generating a matrix of random numbers, denoted $r_{j}^{I}$ (where $I=1 \ldots N$ and $j=1$. 
$\ldots n$ ) belonging to a uniform distribution on the interval $[0,1]$. Mutation occurs on individual $I$ gene $j$ if $r_{j}^{I} \leq p_{m u t, j}$. If a gene is selected for mutation, then one of two types of equiprobable mutation occur. In the first (Eq. 15a) the gene is simply replaced with a randomly generated value. In the second, the gene is replaced with an excursion from its current value (Eq. 15b):

$$
\begin{gathered}
C_{j}^{I}=a_{j, \text { min }}+r\left(a_{j, \text { max }}-a_{j, \text { min }}\right) \\
C_{\mathrm{j}}^{I}=C_{\mathrm{j}}^{I}+s v_{\text {mut }}\left(a_{j, \text { max }}-a_{j, \text { min }}\right)
\end{gathered}
$$

In Eq. $15 \mathrm{a}, r$ is a random number on the interval $[0,1]$, and in Eq. $15 \mathrm{~b} s$ is a random number on the interval $[-0.5,0.5]$. The user-specified parameter $v_{m u t}$ controls the severity of the mutation and is generally less than 1 .

\subsection{Replacement}

The final step in the genetic algorithm is to replace the parents with the offspring. In the algorithm used here, the offspring (i.e. the individuals in the intermediate population) completely replace the parents:

$$
A^{I}(\ell+1)=C^{I}(\ell) \quad \text { for } I=1,2,3, \ldots N
$$

The processes of selection, reproduction, and mutation and replacement are repeated until a predetermined number of generations has passed or the solution converges, meaning no further improvement of the solution occurs with subsequent generations.

\section{Methodology Application and Results}


Before using the above-described methodology to estimate material properties from Cone Calorimeter data, it is first applied to an idealized case where simulated experimental data are generated with the FDS v4.0 charring pyrolysis model. This is done to evaluate the methodology's ability to find a set of eight material properties for a case where the actual material properties are known and the model is an accurate representation of the physical problem. Once the methodology is verified, it is then applied to estimate the material properties of a thermoplastic material (polypropylene) and two charring materials (red oak and redwood) using surface temperature and mass loss rate histories in the Cone Calorimeter [20].

When using the FDS pyrolysis model, 10 grid points are specified per mm of sample thickness, so that the average grid spacing is $0.1 \mathrm{~mm}$ (the FDS pyrolysis model clusters the grid points near the exposed surface). A convective heat transfer coefficient of $10 \mathrm{~W} / \mathrm{m}^{2} \cdot \mathrm{K}$ is assumed, and the emissivity of all materials is set at $\varepsilon=0.9$. A constant flame heat flux of $30 \mathrm{~kW} / \mathrm{m}^{2}$, consistent with experimental measurements in the Cone Calorimeter [20], is added to applied external radiation level after the experimentally determined ignition time. The genetic algorithm is run with a population size of 250, a target (maximum) selection rate of $S=6$, a mutation severity of $v_{m u t}=0.1$, and the exponent $\zeta$ in Eq. 10 is set to 3 . The property-specific genetic algorithm parameters are listed in Table 1; for properties with a "Y" in the "log" column, the base 10 logarithm of that property is used as the gene.

\subsection{Simulated material}


To test the methodology's capabilities, a hypothetical charring material with $5 \mathrm{~mm}$ thickness and a virgin density of $420 \mathrm{~kg} / \mathrm{m}^{3}$ is used to generate simulated experimental data. Its other properties are indicated in Table 2. Three heat flux levels are used: $30 \mathrm{~kW} / \mathrm{m}^{2}, 60 \mathrm{~kW} / \mathrm{m}^{2}$, and $90 \mathrm{~kW} / \mathrm{m}^{2}$, and the ignition times were arbitrarily chosen to be $100 \mathrm{~s}, 50 \mathrm{~s}$, and $25 \mathrm{~s}$, respectively. In addition to surface temperature and mass loss rate, the back-face temperature was also used to evaluate the fitness. All three $\phi$ values were set to $1 / 3$.

The evolution of the population-averaged fitness and the fitness of the best individual found at any point during the evolution process are shown in Fig. 2. By 100 generations, the highest fitness found at any point in the evolution process reached 0.987 (a fitness of 1.0 is a perfect match). The average fitness, an indication of the quality of the "gene pool", increases rapidly for the first $\sim 200$ generations but plateaus thereafter. By the $1000^{\text {th }}$ generation, the fitness of the best individual reached 0.995 . For practical situations, it would have been adequate to stop the algorithm after $\sim 500$ generations, requiring approximately 2 hours of CPU time on a $3.2 \mathrm{GHz}$ desktop PC.

A comparison of the simulated experimental surface temperature and mass loss rate at $60 \mathrm{~kW} / \mathrm{m}^{2}$ with the model predictions using the optimal material properties found by the genetic algorithm is given in Fig. 3. It is seen that the agreement is excellent, which verifies the methodology's capabilities to estimate material properties from experimental data.

Table 2 gives a comparison of the optimal values found by the genetic algorithm and the actual values used to generate the simulated experimental data. The algorithm matched all properties 
within $\sim 10 \%$, with the exception of the char specific heat and the pre-exponential factor. Apparently, the slightly lower value of the heat of pyrolysis found by the genetic algorithm compensates for the higher value of the char specific heat because the model predictions match the simulated experimental data quite well. The slightly lower value of the pre-exponential factor found by the genetic algorithm is compensated for by the slightly lower activation energy. This compensation effect between the pre-exponential factor and the activation energy has long been observed to occur in the estimation of pyrolysis kinetics parameters from thermogravimetric analysis $[21,22]$. Due to the kinetic compensation effect, the algorithm may not find the "true" values of the pre-exponential factor and the activation energy, but it will find values of these parameters that match the Arrhenius function over the temperature range within which pyrolysis occurs.

\subsection{Materials tested in the Cone Calorimeter}

The above methodology is applied in this section to estimate the material properties of a thermoplastic material (polypropylene) and two charring materials (red oak and redwood) for which Cone Calorimeter data are available [20]. The tests simulated are summarized in Table 3. Since no density values are given [20], the density for polypropylene is taken from Ref. [23] and the virgin densities for redwood and red oak are taken from Ref. [24]. The experimental data for surface temperature and mass loss rate were not available in spreadsheet form, so discrete data points were fit to the temperature plots. However, this was not possible with the mass loss rate data due to the large number of closely spaced points and scatter in the experimental data. Therefore, a smooth line was fit to the experimental data. It should be pointed out that genetic 
algorithms do not require smooth data sets; in fact, one of their advantages is that they work well with noisy data.

Figs. 4 through 9 give a comparison of the experimental data and the model predictions using the optimal material properties found by the GA after 1000 generations. Although the measured surface temperature is shown after the samples ignited, for the purposes of matching the model predictions to the experimental data it was used only used prior to the experimentally recorded ignition time listed in Table 3.

Fig. 4 gives a comparison of the polypropylene material's measured surface temperature and that predicted with the FDS thermoplastic pyrolysis model at 34 and $61 \mathrm{~kW} / \mathrm{m}^{2}$. It can be seen that there is good agreement between the model predictions and the experimental data prior to ignition. After ignition, the measured and calculated surface temperatures diverge. This is probably due to separation of the thermocouple from the fuel surface in the experiments. There is very good agreement between the predicted and measured mass loss rate, as shown in Fig. 5. This suggests that the simple thermoplastic pyrolysis model used by FDS, where the pyrolysis rate is a function only of the surface temperature, is capable of reproducing quite well the mass loss rate curves of thermoplastic materials despite the noted limitations of this approach [7].

Fig. 6 gives a comparison of the modeled and predicted surface temperatures for redwood. At a heat flux of $21 \mathrm{~kW} / \mathrm{m}^{2}$, the measured surface temperature is underpredicted after $100 \mathrm{~s}$. At 42 $\mathrm{kW} / \mathrm{m}^{2}$, the predicted and measured surface temperatures match well. Fig. 7 gives the measured 
and calculated mass loss rate histories, and the model predictions match the experiments quite well.

Fig. 8 gives a comparison of the predicted and measured surface temperatures for red oak at 27 $\mathrm{kW} / \mathrm{m}^{2}$ and $76 \mathrm{~kW} / \mathrm{m}^{2}$. At $27 \mathrm{~kW} / \mathrm{m}^{2}$, the surface temperature is slightly underpredicted prior to ignition, but at $76 \mathrm{~kW} / \mathrm{m}^{2}$ it is slightly overpredicted. It is interesting to note that after ignition, the model prediction matches the measured surface temperature at $76 \mathrm{~kW} / \mathrm{m}^{2}$ quite well; similarly, at $27 \mathrm{~kW} / \mathrm{m}^{2}$ the predicted surface temperature trend after ignition matches the experiment, although the model underpredicts the temperature by $\sim 50 \mathrm{~K}$. The predicted and measured mass loss rate histories are compared in Fig. 9, and it can be seen that there is good agreement.

The material properties corresponding to the individual with the highest fitness after 1000 generations are summarized in Table 4, with literature values given for comparison (where available). For the polypropylene material, the values of $k_{v}, c_{v}$, and $\Delta H_{p}$ are relatively close to the literature values. It should be noted that the Arrhenius parameters cannot be directly compared to literature values because in the model used here, the pyrolysis is forced to occur at the surface. Unfortunately, no literature values were located specifically for redwood or red oak. However, the values used by Ritchie et al. [6] for Douglas Fir are listed in Table 4 to provide a rough point of reference. The properties found by the GA for redwood and red oak all seem reasonable, although the thermal conductivity of the red oak char seems high. Radiative heat transfer in the porous char becomes important experimentally at high temperatures, but this effect is not 
accounted for by the FDS pyrolysis model. Ths may partially explain the relatively high value of thermal conductivity for red oak char found by the GA.

\section{Concluding remarks}

The feasibility of estimating the material properties needed for CFD-based fire growth modeling from small-scale fire tests has been demonstrated using a methodology based on matching a pyrolysis model's predictions to the experimental data via genetic algorithm optimization. Transient measurements of surface temperature and mass loss rate in the Cone Calorimeter were used as the metric against which the "accuracy" of the model predictions was judged. The model parameters (material properties) were automatically adjusted to find a parameter set that provides near-optimal agreement between the model predictions and the experimental data given the constraints imposed by the simplified nature of the underlying physical model and the accuracy with which the experimental boundary conditions, particularly the flame heat flux, can be specified. The generally satisfactory level of agreement between the model predictions and the experimental data is encouraging. However, it remains to be seen whether material properties obtained with this methodology can be used to accurately model large-scale fire development, and this is recommended for future work.

Although the genetic algorithm optimization technique developed here is heuristic, the results presented in Section 4.1 using simulated experimental data suggest that it is capable of finding most model parameters within $\sim 10 \%$ for this idealized situation. However, when using this methodology to estimate material properties from an actual fire test, the complex physical 
processes occurring in that test are by necessity simulated with a comparatively simple physical model. For example, all thermal properties are assumed independent of temperature here for simplicity (although, it is possible to use this approach to find temperature-dependent material properties by assuming a functional dependence on temperature). Therefore, the material properties found by the genetic algorithm should be interpreted as average values over the range of test conditions considered. Furthermore, they are influenced by the simplifying assumptions built into the pyrolysis model. It is possible that a set of properties found to provide the best agreement between the predictions and experiments using one pyrolysis model will not do the same when used with another model if it is based on different physics or simplifying assumptions. In this sense, they are not true properties of a material, but rather the pyrolysis model input parameters that were found to provide near-optimal agreement between model predictions and experimental data. However, if the model is physically correct and the experimental data corresponds to a fundamental fire process, there is reason to believe that the properties found with this methodology will provide good results when used with a fire model. Nonetheless, the material properties obtained should be used only with the pyrolysis model from which they were derived, incorporated in a fire model.

There are several advantages to the specific methodology used in this work. It can be used with any pyrolysis model (including models with nonlinear governing equations and a large number of adjustable parameters) and any fire test in which the mass loss rate can be measured. It is selfconsistent because the same model used to extract the material properties from the bench scale fire test data is used to calculate ignition, mass burning, flame spread, and fire growth. All 
properties needed to characterize a material for CFD-based fire modeling can be estimated from a single bench-scale fire test. Practical charring materials can be handled.

Some disadvantages of the proposed method used here are that the flame heat flux is not precisely known and surface temperature measurements are needed. A simple predictive model to estimate the flame heat flux in a particular apparatus for different fuels as a function of mass loss rate and key parameters measured in fire tests (such as the heat of combustion and soot yield) would allow the flame heat flux to be estimated with greater confidence. Alternatively, the mass loss rate measurements could be obtained under nonflaming conditions (i.e., in the absence of a pilot). The sensitivity of the properties determined with this method to the particular experimental apparatus used must also be investigated.

\section{Acknowledgments}

This work was supported by NASA Glenn Research Center under Grant NNC-05GA02G. The first author would also like to thank NASA for support under the Graduate Student Researcher Program, Grant NNC-04HA08H, sponsored by NASA Glenn Research Center.

\section{References}

1. Zhou YY, Walther DC, Fernandez-Pello, AC. Theoretical Predictions of Piloted Ignition of Polymeric Fuels in Microgravity at Low Velocity Flows. Microgravity Sci Tech $2003 ; 14: 44-50$. 
2. ASTM E1354-03, Standard Test Method for Heat and Visible Smoke Release Rates for Materials and Products Using an Oxygen Consumption Calorimeter.

3. ASTM E2058-03, Standard Test Methods for Measurement of Synthetic Polymer Material Flammability Using a Fire Propagation Apparatus (FPA).

4. McGrattan KB, Forney GP, Floyd JE, Hostikka S, Prasad K. Fire Dynamics Simulator (Version 4) - User's Guide. National Institute of Standards and Technology, NISTIR 6784, 2004.

5. Atreya A. Pyrolysis, Ignition, and Fire Spread on Horizontal Surfaces of Wood. National Bureau of Standards, Technical Report GCR 83-449, 1983.

6. Ritchie SJ, Steckler KD, Hamins A, Cleary TG, Yang JC, Kashiwagi, T. The Effect of Sample Size on the Heat Release Rate of Charring Materials. Fire Safety Science-Proceedings of the Fifth International Symposium, International Association for Fire Safety Science, pp 177-188, 1997.

7. Vovelle C, Delfau J, Reuillon M, Bransier J, Laraqui N. Experimental and Numerical Study of the Thermal Degradation of PMMA. Combust. Sci. Tech. 1987;53:187-201.

8. Quintiere JG. Simplified Theory for Generalizing Results from a Radiant Panel Rate of Flame Spread Apparatus. Fire Materials 1981;5:52-60.

9. Babrauskas V. Ignition Handbook. Fire Science Publishers, Issaquah, WA, 2003. pg 263.

10. Cordova JL, Walther DC, Torero JL, Fernandez-Pello AC. Oxidizer Flow Effects on the Flammability of Solid Combustibles. Combust Sci Tech 2001;164:253-278.

11. Mowrer FW. An Analysis of Effective Thermal Properties of Thermally Thick Materials. Fire Safety J 2005; (in press). 
12. Vyazovkin S, Wight CA. Isothermal and Non-Isothermal Kinetics of Thermally Stimulated Reactions of Solids. Int Rev Phy Chem 1998;17:407-433.

13. Tewarson A, Pion RF. Flammability of Plastics. I. Burning Intensity. Combust Flame 1976;26:85-103.

14. Park TY, Froment GF. A Hybrid Genetic Algorithm for the Estimation of Parameters in Detailed Kinetic Models. Computers Chem Eng 1998;22:S103-S110.

15. Elliott L, Ingham DB, Kyne AG, Mera NS, Pourkashanian M, Wilson CW. Genetic algorithms for optimisation of chemical kinetics reaction mechanisms. Prog Energy Comb Sci 2004; 30:297-328.

16. Rein G, Lautenberger C, Fernandez-Pello, AC, Torero JL, Urban DL. Application of Genetic Algorithms and Thermogravimetry to Determine the Kinetics of Polyurethane Foam in Smoldering Combustion. Submitted to Combust Flame, 2005.

17. Goldberg D. Genetic Algorithms: In Search, Optimization \& Machine Learning. Addison-Wesley Publishing Company, Inc., Menlo Park, 1989.

18. Michalewicz Z. Genetic Algorithms + Data Structures $=$ Evolution Programs. SpringerVerlag, New York, 1992.

19. Dumitrescu D, Lazzerini B, Jain LC, Dumitrescu A. Evolutionary Computation. CRC Press, New York, 2000.

20. Hopkins D. Prediction the Ignition Time and Burning Rate of Thermoplastics in the Cone Calorimeter. National Institute of Standards and Technology, Technical Report GCR-95$667,1995$.

21. Narayan R, Antal MJ Jr. Thermal Lag, Fusion, and the Compensation Effect during Biomass Pyrolysis. Ind Eng Chem Res 1996; 35:1711-1721. 
22. Naian L, Binghong W, Weicheng F. Kinetic Compensation Effect in the Thermal Decomposition of Biomass in air Atmosphere. Fire Safety Science - Proceedings of the Seventh International Symposium, Ed. Evans DD, 2003; 581-592.

23. Zhou YY, Fernandez-Pello AC. Numerical Modeling of Endothermic Pyrolysis and Ignition Delay of Composite Materials Exposed to an External Radiant Heat Flux. Proc Comb Inst 2000;28:2769-2775.

24. White RH, Dietenberger MA, Tran H, Grexa O, Richardson L, Sumathipala K, Janssens M. Comparison of Test Protocols for the Standard Room/Corner Test. Fire Materials $2000 ; 23: 139-146$. 


\section{List of figures}

Fig. 1. Simplified schematic of the physical problem.

Fig. 2. Evolution of average and best fitness to 1000 generations for simulated experimental data case.

Fig. 3. Comparison of simulated experimental data and model predictions using optimal material properties determined by genetic algorithm after 1000 generations. Heat flux is $60 \mathrm{~kW} / \mathrm{m}^{2}$.

Fig. 4. Comparison of experimental polypropylene surface temperature measurement with model prediction using parameters found by GA.

Fig. 5. Comparison of experimental polypropylene mass loss rate with model prediction using parameters found by GA.

Fig. 6. Comparison of experimental redwood surface temperature measurement with model prediction using parameters found by GA.

Fig. 7. Comparison of experimental redwood mass loss rate with model prediction using parameters found by GA.

Fig. 8. Comparison of experimental red oak surface temperature measurement with model prediction using parameters found by GA.

Fig. 9. Comparison of experimental red oak mass loss rate with model prediction using parameters found by GA. 


\section{List of tables}

Table 1. Input parameters to genetic algorithm.

Table 2. Comparison of actual material properties used to generate simulated experimental data and material properties found with genetic algorithm.

Table 3. Experimental materials.

Table 4. Comparison of optimal material properties found with genetic algorithm and literature values. For PP, Arrhenius properties given for thermal pyrolysis. Temperature-dependent properties for PP and Douglas fir evaluated at $200^{\circ} \mathrm{C}$.

List of Tables 


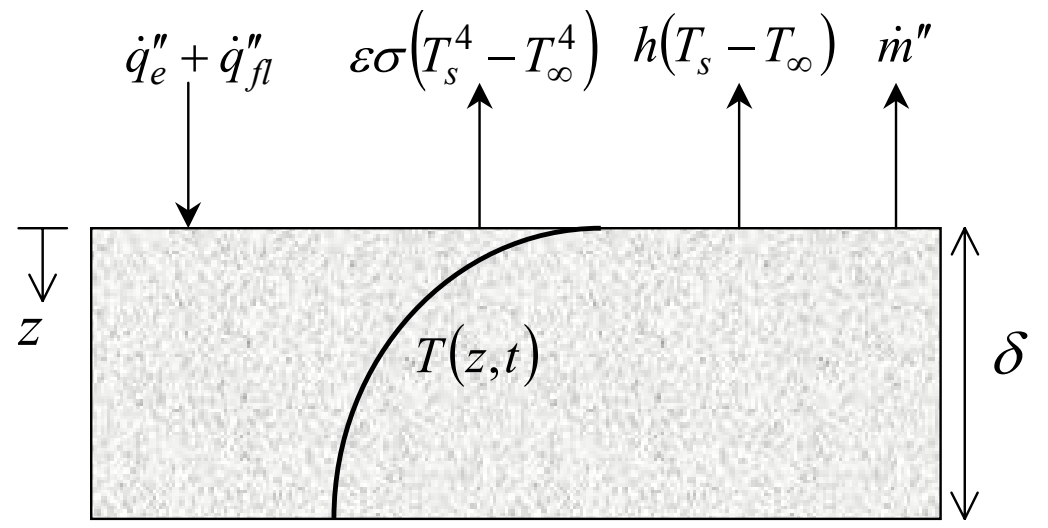

Fig. 1. Simplified schematic of the physical problem.

Figure 1 


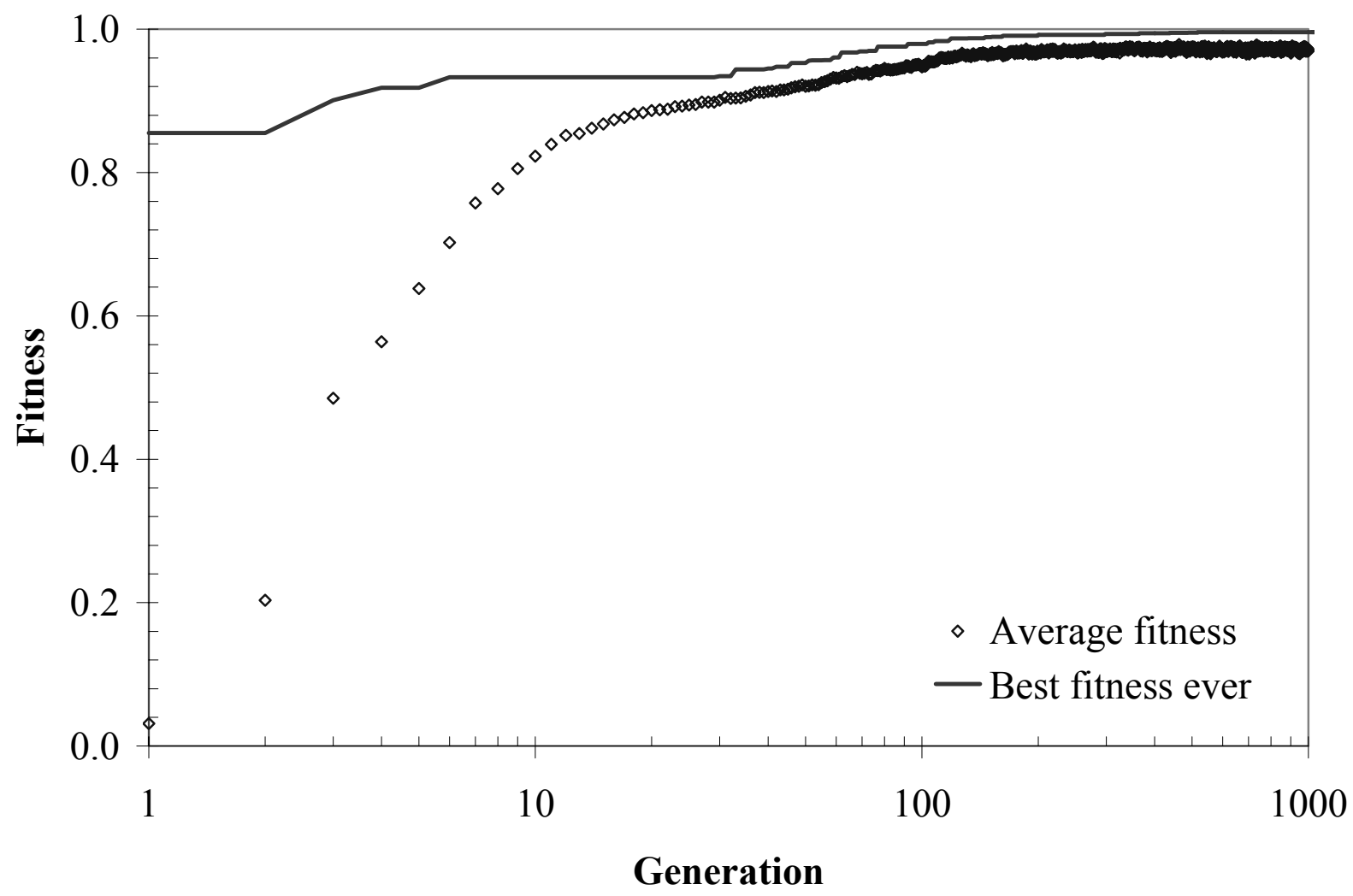

Fig. 2. Evolution of average and best fitness to 1000 generations for simulated experimental data case.

Figure 2 


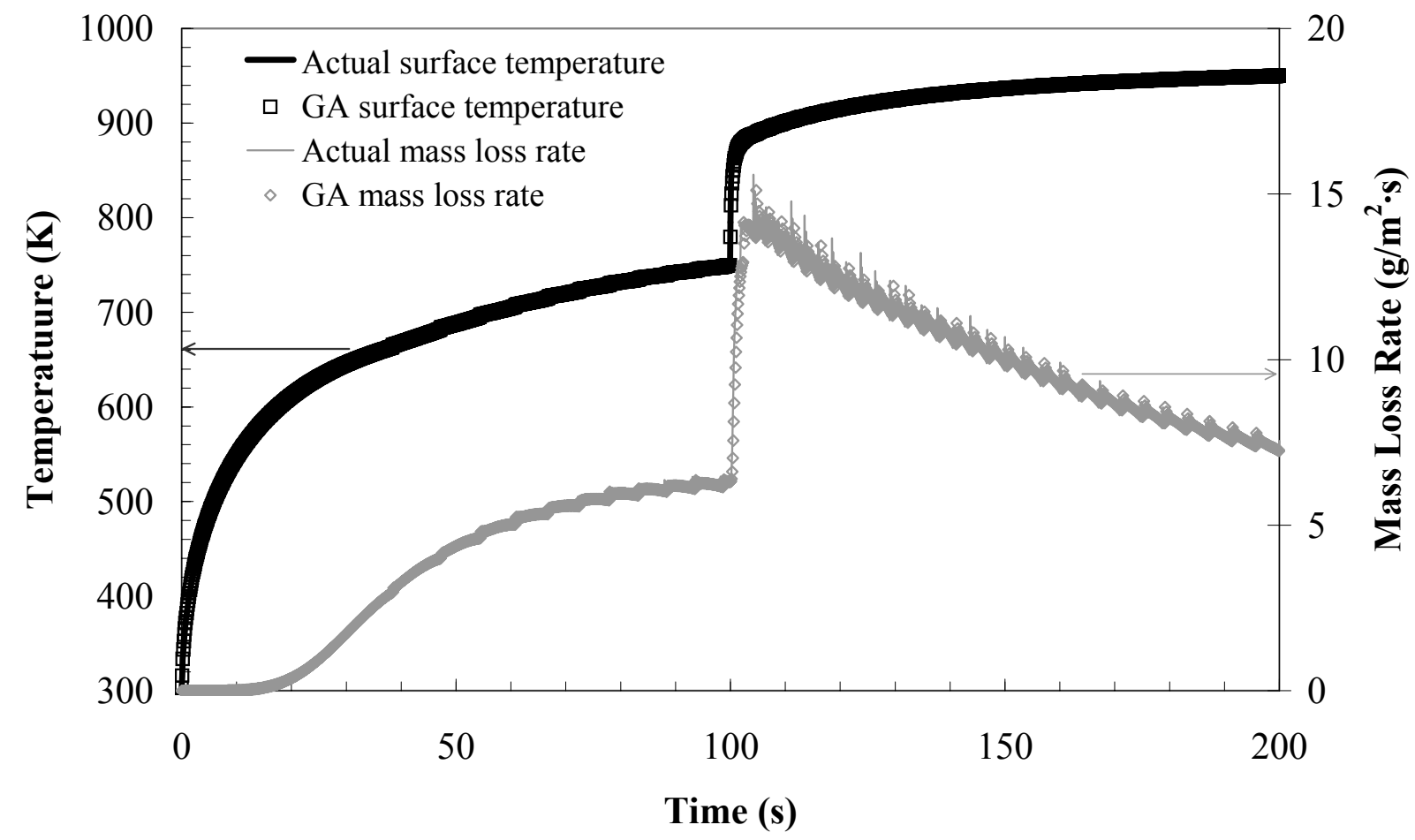

Fig. 3. Comparison of simulated experimental data and model predictions using optimal material properties determined by genetic algorithm after 1000 generations. Heat flux is $60 \mathrm{~kW} / \mathrm{m}^{2}$.

Figure 3 


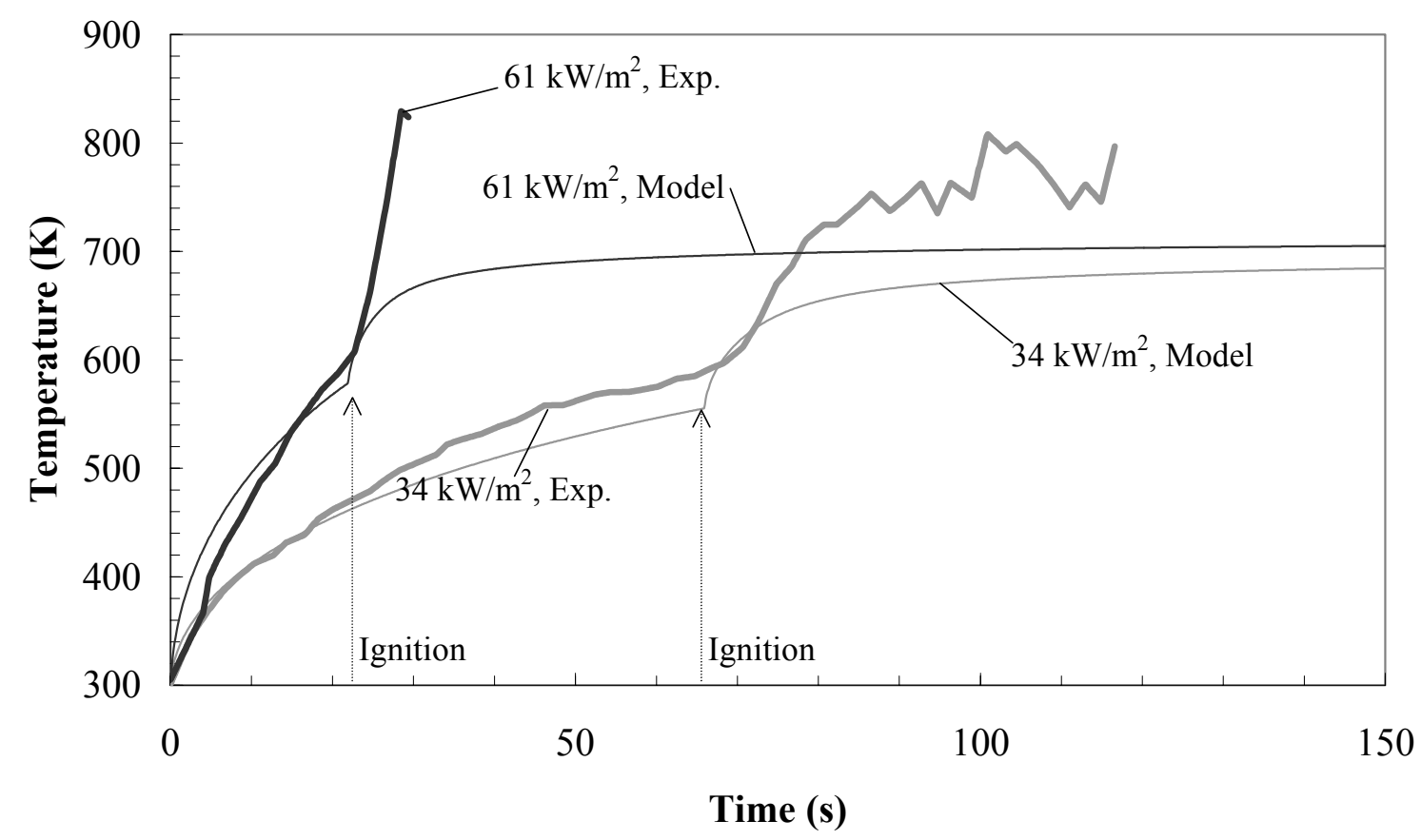

Fig. 4. Comparison of experimental polypropylene surface temperature measurement with model prediction using parameters found by GA.

Figure 4 


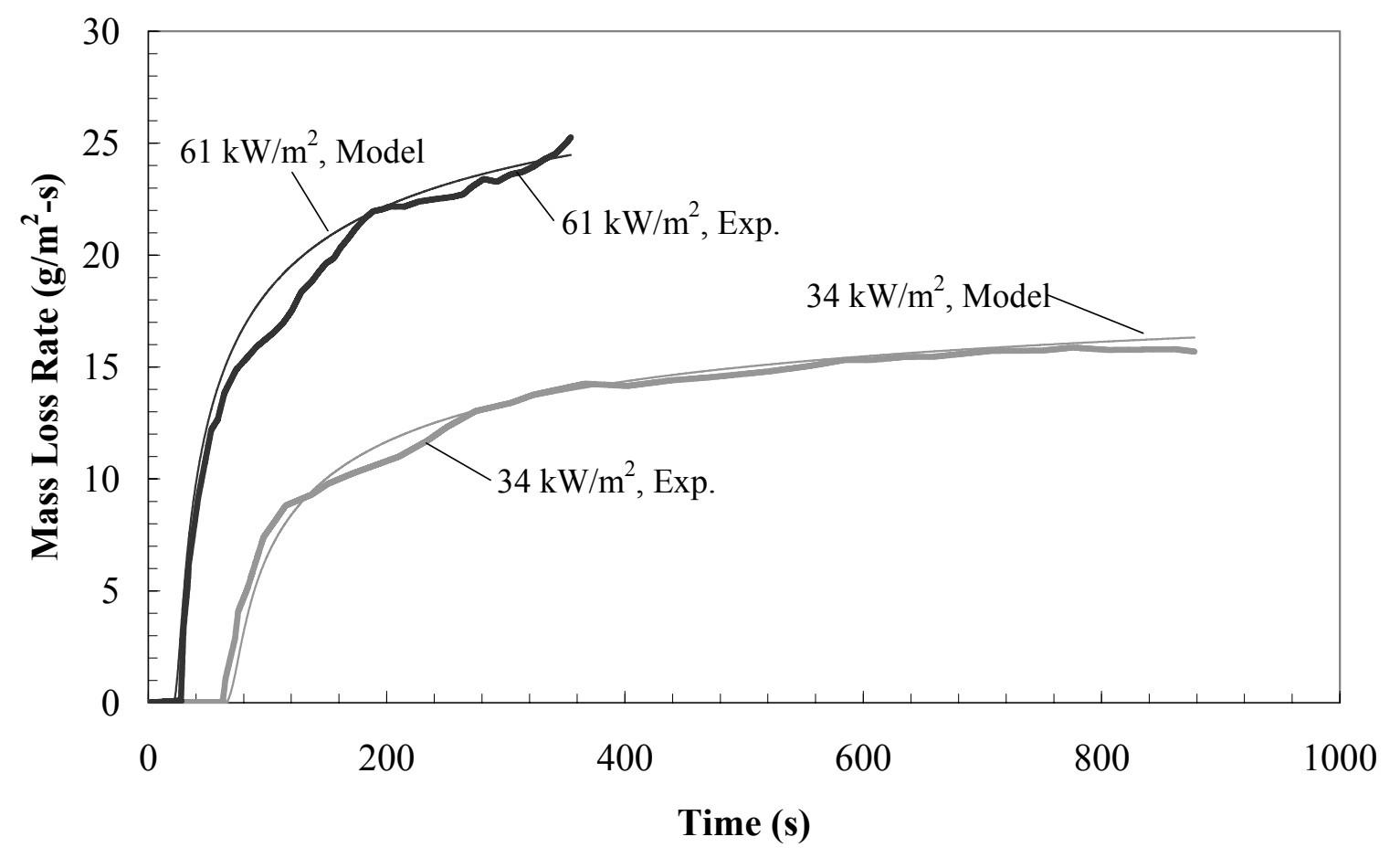

Fig. 5. Comparison of experimental polypropylene mass loss rate with model prediction using parameters found by GA.

Figure 5 


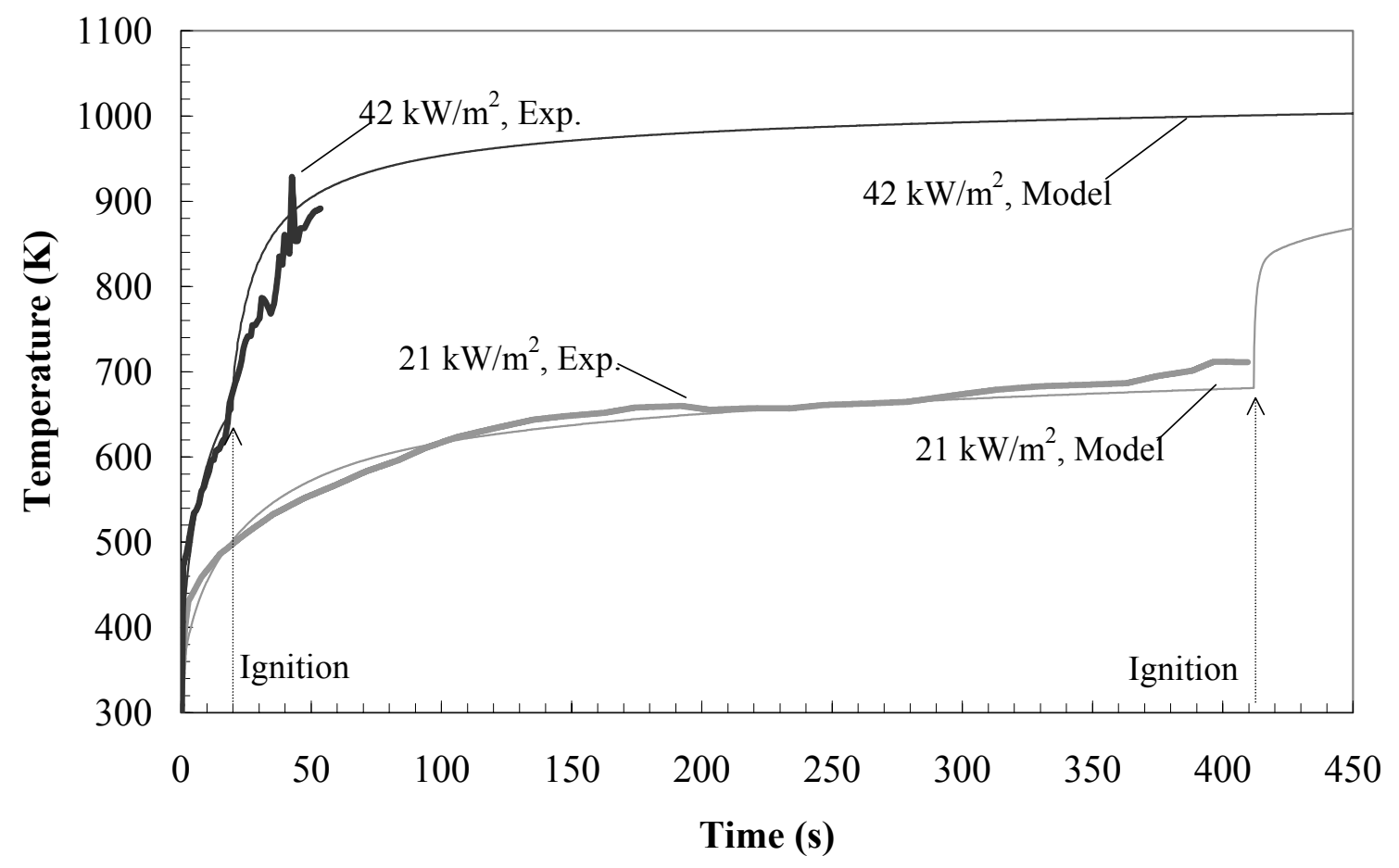

Fig. 6. Comparison of experimental redwood surface temperature measurement with model prediction using parameters found by GA.

Figure 6 


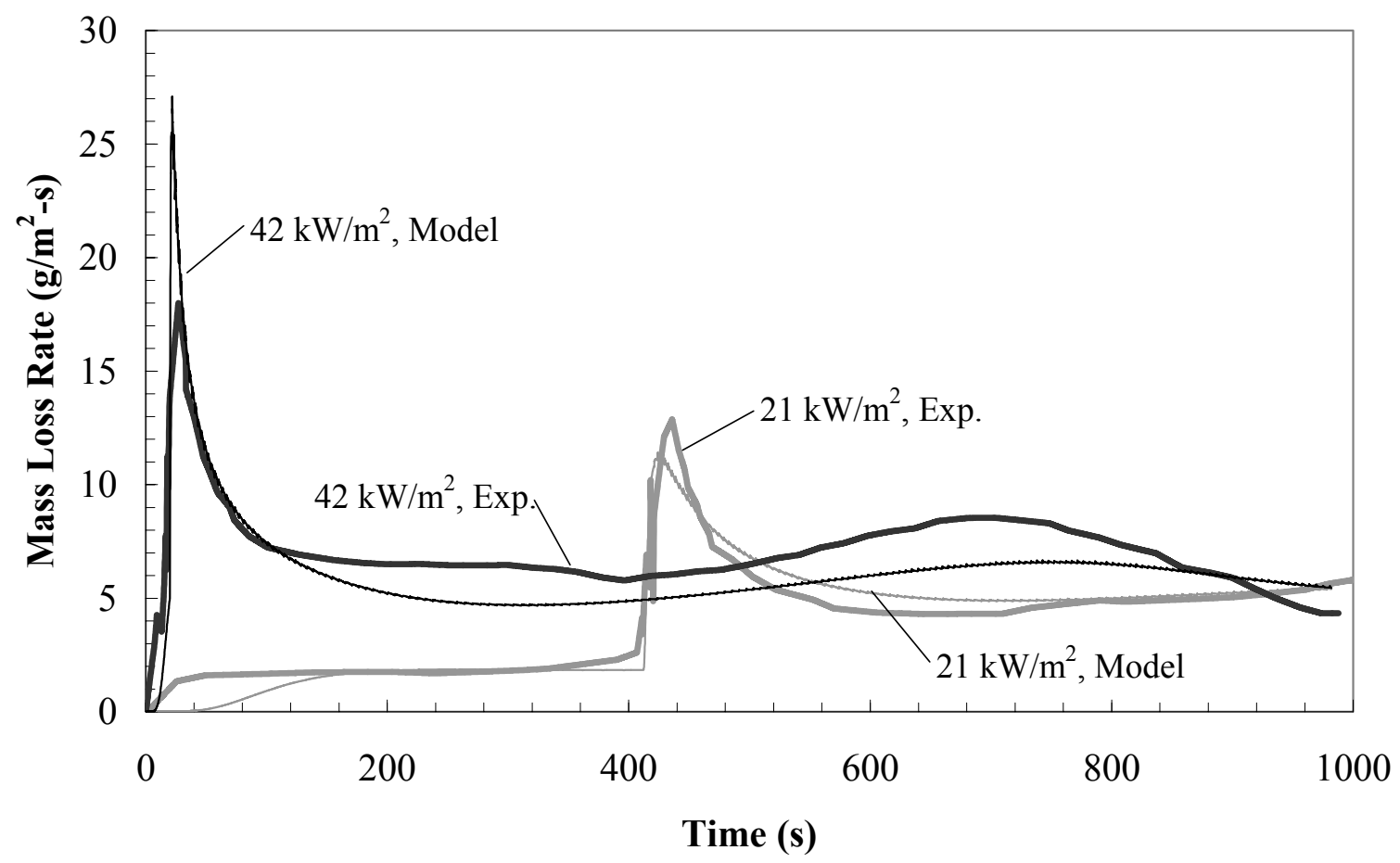

Fig. 7. Comparison of experimental redwood mass loss rate with model prediction using parameters found by GA.

Figure 7 


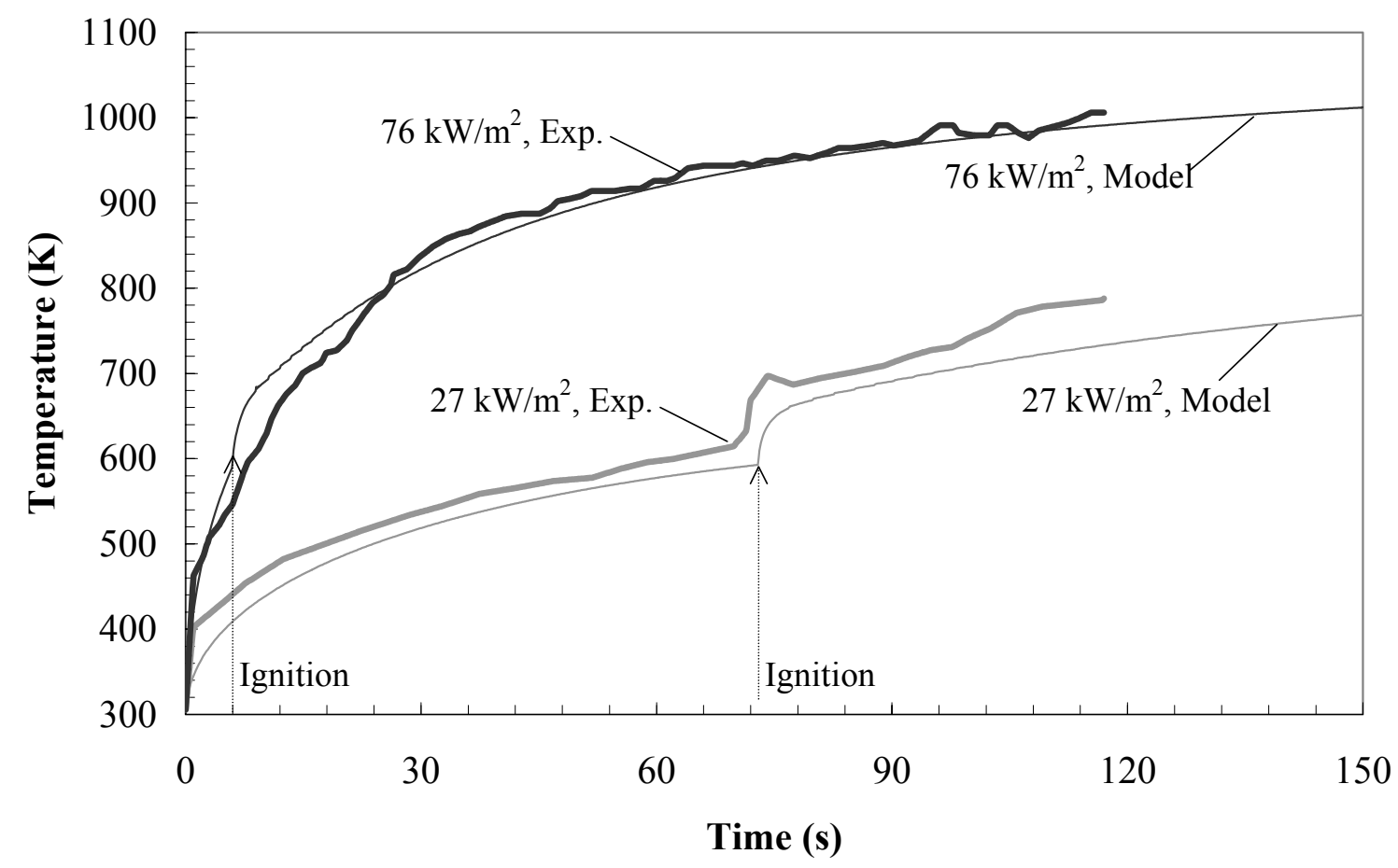

Fig. 8. Comparison of experimental red oak surface temperature measurement with model prediction using parameters found by GA.

Figure 8 


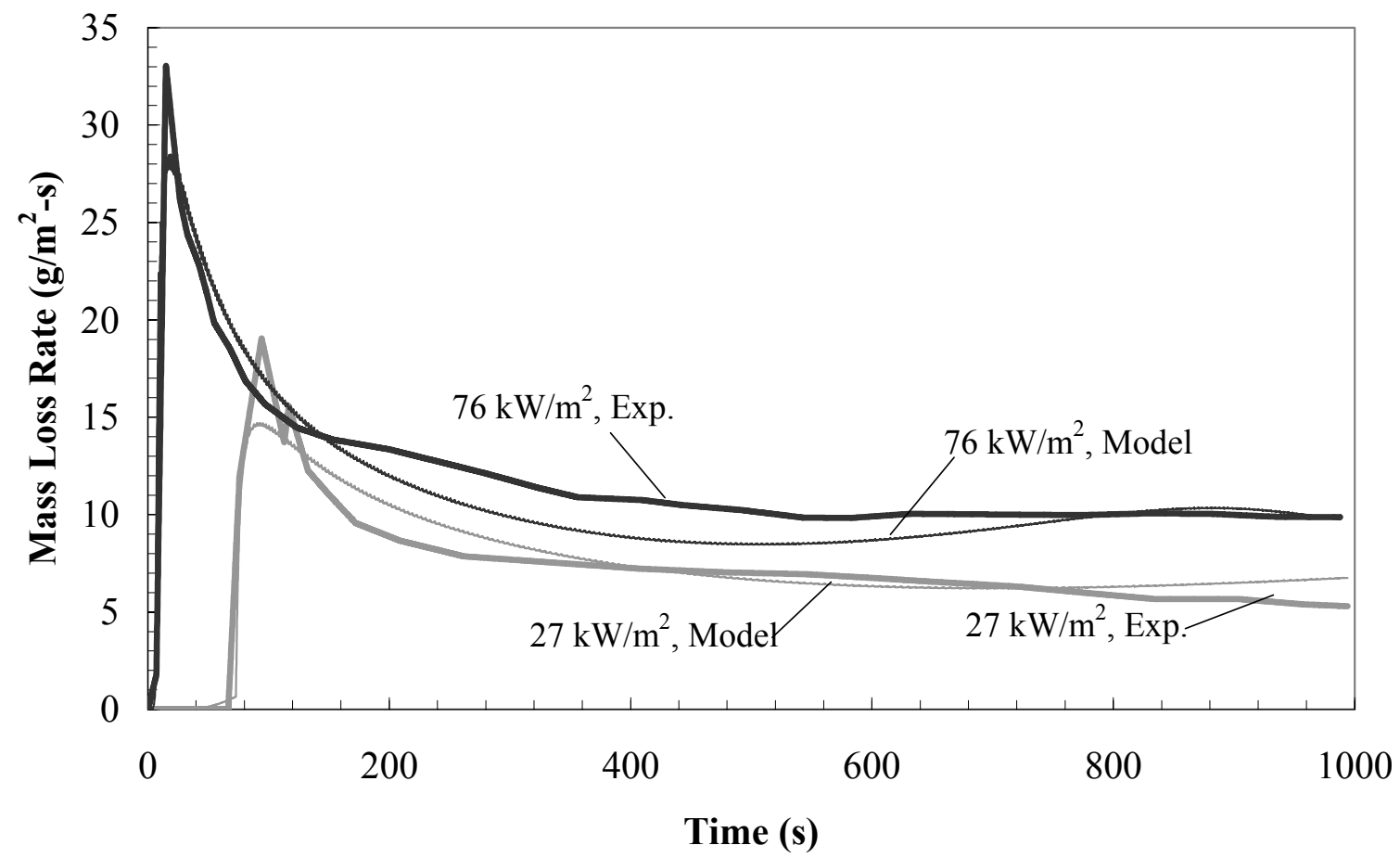

Fig. 9. Comparison of experimental red oak mass loss rate with model prediction using parameters found by GA.

Figure 9 
Table 1. Input parameters to genetic algorithm.

\begin{tabular}{ccccc}
\hline Parameter & $p_{\text {mut }}$ & Log & $a_{\min }$ & $a_{\max }$ \\
\hline$k_{v}[\mathrm{~W} / \mathrm{m} \cdot \mathrm{K}]$ & 0.05 & $\mathrm{~N}$ & 0.05 & 1 \\
$c_{v}[\mathrm{~kJ} / \mathrm{kg} \cdot \mathrm{K}]$ & 0.05 & $\mathrm{~N}$ & 0.5 & 5 \\
$Z[\mathrm{~m} / \mathrm{s}]$ & 0.10 & $\mathrm{Y}$ & $10^{4}$ & $10^{10}$ \\
$E_{a}[\mathrm{~kJ} / \mathrm{mol}]$ & 0.10 & $\mathrm{~N}$ & 60 & 250 \\
$\Delta H_{p}[\mathrm{~kJ} / \mathrm{kg}]$ & 0.20 & $\mathrm{Y}$ & $10^{2}$ & $10^{4}$ \\
$k_{c}[\mathrm{~W} / \mathrm{m} \cdot \mathrm{K}]$ & 0.20 & $\mathrm{~N}$ & 0.05 & 1 \\
$c_{c}[\mathrm{~kJ} / \mathrm{kg} \cdot \mathrm{K}]$ & 0.20 & $\mathrm{~N}$ & 0.5 & 5 \\
$\rho_{c}\left[\mathrm{~kg} / \mathrm{m}^{3}\right]$ & 0.20 & $\mathrm{~N}$ & 20 & $\rho_{v}$ \\
\hline
\end{tabular}

Table 1 
Table 2. Comparison of actual material properties used to generate simulated experimental data and material properties found with genetic algorithm.

\begin{tabular}{cccc}
\hline Property & Actual & GA & \% Error \\
\hline$k_{v}[\mathrm{~W} / \mathrm{m} \cdot \mathrm{K}]$ & 0.200 & 0.195 & $-2.5 \%$ \\
$c_{v}[\mathrm{~kJ} / \mathrm{kg} \cdot \mathrm{K}]$ & 1.50 & 1.49 & $-0.7 \%$ \\
$Z[\mathrm{~m} / \mathrm{s}]$ & $8.30 \times 10^{7}$ & $3.73 \times 10^{7}$ & $-55.1 \%$ \\
$E_{a}[\mathrm{~kJ} / \mathrm{mol}]$ & 163.0 & 159.1 & $-2.4 \%$ \\
$\Delta H_{p}[\mathrm{~kJ} / \mathrm{kg}]$ & 1000 & 893 & $-10.7 \%$ \\
$k_{c}[\mathrm{~W} / \mathrm{m} \cdot \mathrm{K}]$ & 0.100 & 0.107 & $7.0 \%$ \\
$c_{c}[\mathrm{~kJ} / \mathrm{kg} \cdot \mathrm{K}]$ & 1.00 & 1.96 & $96.0 \%$ \\
$\rho_{c}\left[\mathrm{~kg} / \mathrm{m}^{3}\right]$ & 100 & 98.6 & $-1.4 \%$ \\
\hline
\end{tabular}

Table 2 
Table 3. Experimental materials.

\begin{tabular}{ccccc}
\hline Material & $\begin{array}{c}\rho_{v} \\
\left(\mathrm{~kg} / \mathrm{m}^{3}\right)\end{array}$ & $\begin{array}{c}\delta[20] \\
(\mathrm{cm})\end{array}$ & $\begin{array}{c}\dot{q}_{e}^{\prime \prime}[20] \\
\left(\mathrm{kW} / \mathrm{m}^{2}\right)\end{array}$ & $\begin{array}{c}t_{i g}[20] \\
(\mathrm{s})\end{array}$ \\
\hline Polypropylene & $900[23]$ & 2.5 & 34 & 66 \\
& & & 61 & 22 \\
Redwood & $420[24]$ & 1.91 & 21 & 412 \\
& & & 42 & 20 \\
Red Oak & $624[24]$ & 3.18 & 27 & 73 \\
\hline
\end{tabular}

Table 3 
Table 4. Comparison of optimal material properties found with genetic algorithm and literature values. For PP, Arrhenius properties given for thermal pyrolysis. Temperature-dependent properties for $\mathrm{PP}$ and Douglas fir evaluated at $200^{\circ} \mathrm{C}$.

\begin{tabular}{cccccc}
\hline Property & PP & PP & Redwood & Red oak & Douglas fir \\
& GA & Ref. 23 & GA & GA & Ref. 6 \\
\hline$k_{v}[\mathrm{~W} / \mathrm{m} \cdot \mathrm{K}]$ & 0.29 & 0.24 & 0.22 & 0.42 & 0.18 \\
$c_{v}[\mathrm{~kJ} / \mathrm{kg} \cdot \mathrm{K}]$ & 3.83 & 3.55 & 1.87 & 1.57 & 2.86 \\
$Z[\mathrm{~m} / \mathrm{s}]$ & $6.45 \times 10^{5}$ & $4.6 \times 10^{10}$ & $3.38 \times 10^{7}$ & $1.43 \times 10^{7}$ & $2.5 \times 10^{8}$ \\
$E_{a}[\mathrm{~kJ} / \mathrm{mol}]$ & 141.0 & 243.0 & 154.0 & 147.4 & 126 \\
$\Delta H_{p}[\mathrm{~kJ} / \mathrm{kg}]$ & 2288 & 3000 & 686 & 802 & 126 \\
$k_{c}[\mathrm{~W} / \mathrm{m} \cdot \mathrm{K}]$ & - & - & 0.18 & 0.73 & 0.094 \\
$c_{c}[\mathrm{~kJ} / \mathrm{kg} \cdot \mathrm{K}]$ & - & - & 2.47 & 2.33 & 1.60 \\
$\rho_{c}\left[\mathrm{~kg} / \mathrm{m}^{3}\right]$ & - & - & 101 & 261 & 118 \\
\hline
\end{tabular}

Units are $\mathrm{s}^{-1}$, not m/s 